\title{
BIOPRODUTOS A PARTIR DO ÓLEO VEGETAL RESIDUAL: DESENGRAXANTES BASEADOS EM RESÍDUOS DE ROCHAS E CARVÃO VEGETAL
}

\author{
Bioproducts from residual vegetable oil: degreasing based on residuals from rocks and Vegetable carbon \\ Sérgio Thode Filho', Marcelo Fonseca Monteiro de Sena², Cintia Patrícia Santos da Paixão², \\ Fabíola da Silveira Maranhão ${ }^{4}$, Elmo Rodrigues da Silva ${ }^{5}$
}

\begin{abstract}
'Doutorando em Meio Ambiente pelo PPG-MA da Universidade do Estado do Rio de Janeiro - UERJ, Professor do Instituto Federal de Educação, Ciência e Tecnologia do Rio de janeiro - IFRJ, Campus Duque de Caxias, RJ, Laboratório Multidisciplinar de Gerenciamento de Resíduos - LMGR

${ }^{2}$ Professor do Instituto Federal do Rio de Janeiro - IFRJ, Campus Duque de Caxias, RJ - LMGR

${ }^{3}$ Aluna do Curso Tecnólogo em Gestão Industrial - IFRJ, bolsista pesquisadora do LMGR.

${ }^{4}$ Técnica em Polímeros - IFRJ, bolsista pesquisadora do LMGR

${ }^{5}$ Professor do PPG-MA da Universidade do Estado do Rio de Janeiro - UERJ
\end{abstract}

\begin{abstract}
Resumo
Os óleos vegetais são amplamente utilizados pela população brasileira, seja em nível doméstico, comercial ou industrial. Ao final de seu processamento, o óleo remanescente é descartado, muitas vezes, de forma incorreta, sendo liberado nos efluentes ou diretamente no solo, tornando-se um resíduo potencialmente poluidor. O objetivo deste trabalho é apresentar a obtenção de dois bioprodutos como alternativa mitigadora do impacto ambiental, provocado pelo descarte inadequado do óleo vegetal residual. O processamento inicia-se com a dissolução do sabão sólido em água e homogeneizado em béquer durante 10 minutos até formar uma pasta semi-sólida. Em seguida, foi adicionado $10 \mathrm{~g}$ de pó residual de carvão vegetal, carvão mineral, mármore, granito e/ou outras rochas, homogeneizando-se por 3 minutos. O resultado do processamento descrito na metodologia é uma pasta com característica física semi-sólida, arenosa e com ação esfoliante, quando utilizado pó residual de mármore e/ou granito. Quando utilizado pó residual de carvão vegetal, o resultado é uma coloração escura e ação abrasiva. Este trabalho apresentou a possibilidade de obtenção de dois bioprodutos como alternativas de mitigação do impacto ambiental, provocado pelo descarte inadequado do óleo vegetal residual. Os processos simplificados, as matérias-primas não dispendiosas e os equipamentos rotineiros estimulam positivamente a sua produção.
\end{abstract}

Palavras chave: Bioprodutos, desengraxante, óleo vegetal residual.

\begin{abstract}
Vegetable oils are widely used by the Brazilian population, whether domestic, commercial or industrial level. At the end of processing, the remaining oil is discarded, often incorrectly, or being released in effluents directly into the soil, making it a potentially polluting waste. The objective of this work is to obtain two alternative bioproducts such as mitigating the environmental impact caused by the improper disposal of waste vegetable oil. The processing starts with the dissolution of the solid soap in water in beaker and homogenized for 10 minutes to form a semisolid paste. Then was added 10g of residual charcoal powder, coal, granite, marble and/or other rocks, homogenizing for 3 minutes. The result of the processing described in the methods is a semi-solid paste, sandy exfoliating action and physical characteristic when used residual powder of marble and/or granite. When used residual charcoal powder, the result is a dark color and abrasive action. This work showed the possibility of obtaining two bioproducts as alternatives to mitigate the environmental impact caused by improper disposal of waste vegetable oil. The raw materials not expensive simplified procedures and routine equipment positively stimulate their production.
\end{abstract}

Keywords: Bioproducts, degreaser, waste vegetable oil. 


\section{INTRODUÇÃO}

Os óleos vegetais são amplamente utilizados pela população brasileira, seja em nível doméstico, comercial ou industrial. Ao final de seu processamento, o óleo remanescente é descartado, muitas vezes, de forma incorreta, sendo liberado nos efluentes ou diretamente no solo, tornando-se um resíduo potencialmente poluidor (RABELO \& FERREIRA, 2008; SABESP, 2011).

No município do Rio de Janeiro mais de 20 milhões de litros de óleo vegetal são consumidos por ano. Em 2008, apenas 50 mil litros, ou 0,2\%, foram reciclados. Em 2009, com a implementação do Programa de Reaproveitamento de Óleos Vegetais do Estado do Rio de Janeiro (PROVE), foram recolhidos cerca de 60 mil litros nos três primeiros meses do ano (FOLHA DO CENTRO, 2009).

Não há um consenso quanto à forma ideal de descarte do óleo vegetal residual. A orientação mais comum quanto ao seu descarte é o acondicionamento do óleo em um recipiente fechado, como uma garrafa pet, seguido do descarte no lixo domiciliar. A desvantagem deste procedimento é a incerteza de que este resíduo não alcance os corpos hídricos e solos, uma vez que a coleta de lixo domiciliar por caminhões compactadores pode causar o rompimento dos recipientes (RABELO \& FERREIRA, 2008). O objetivo deste trabalho é apresentar a obtenção de dois bioprodutos como alternativa mitigadora do impacto ambiental, provocado pelo descarte inadequado do óleo vegetal residual.

\section{METODOLOGIA}

O óleo vegetal residual utilizado neste trabalho foi oriundo de doações voluntárias de moradores de diversas localidades do Município de Duque de Caxias, Rio de Janeiro. O material foi entregue, necessariamente acondicionado em garrafas polietileno PET de $500 \mathrm{~mL}$ a $2 \mathrm{~L}$ no posto de entrega voluntária situado no Laboratório Multidisciplinar de Gerenciamento de Resíduos (LMGR), no Instituto Federal de Educação, Ciência e Tecnologia do Rio de Janeiro campus Duque de Caxias. No laboratório, procedeu-se com a filtração do óleo doado para retirada dos resíduos sólidos e em seguida acondicionado por um período de dez dias em um tanque de 100L para decantação. Após estes processos físicos iniciais procedeu-se dois teste químicos que foi o índice de acidez com $2,15 \%$ e o índice de peróxido com
$1,85 \mathrm{meq} / \mathrm{kg}$. Após estes processos iniciou-se a produção dos bioprodutos.

O sabão sólido foi produzido de acordo com Thode-Filho et al. (2013), onde o óleo vegetal residual é medido na proporção $1: 2: 6$, isto é uma parte de $\mathrm{NaOH}$, duas partes de água e seis partes do óleo residual. Constatou-se que na relação utilizada, não foram encontradas presença de soda livre, presença de óleo e água que não foram totalmente utilizados no processo de reação. Percebe-se que mesmo sem a utilização de essências ou aromatizantes o produto final apresenta um aspecto físico uniforme, uma textura rígida, uma coloração amarelo pálido, um odor agradável, um índice de espuma satisfatório e um $\mathrm{pH}$ aceitável. O sabão produzido com estes insumos são indicados para uso em limpeza pesada, sendo impróprios para o asseio corporal.

Após este processamento prévio, procedeu-se com a produção do desengraxante. Os materiais utilizados nesta finalidade são: béquer de $200 \mathrm{~mL}$, bastão de vidro, espátula, óculos, luva e máscara de segurança e os insumos foram $50 \mathrm{~g}$ de massa de sabão sólido produzido com óleo vegetal residual, $25 \mathrm{~mL}$ de água e $10 \mathrm{~g}$ de pó residual de carvão vegetal, carvão mineral, mármore, granito e/ou outras rochas. O processamento inicia-se com a dissolução do sabão sólido em água e homogeneizado em béquer durante 20 minutos até formar uma pasta semi sólida. Em seguida, foi adicionado $10 \mathrm{~g}$ de pó residual de carvão vegetal, carvão mineral, mármore, granito e/ou outras rochas, homogeneizando-se por 3 minutos.

\section{RESULTADO E DISCUSSÃO}

O resultado do processamento descrito na metodologia é uma pasta com característica física semi-sólida e arenosa com ação esfoliante (Figura 1a-b) quando utilizado pó residual de mármore e/ou granito; ou com cor escura e ação abrasiva (Figura 1a-c) quando utilizado pó residual de carvão vegetal.

O custo dos insumos associado à obtenção dos bioprodutos é extremamente baixo, pois os equipamentos necessários para a produção são facilmente encontrados em um ambiente doméstico. Os mesmos são descritos na Tabela1.

Algumas composições de desengraxante para uso geral apresentam na sua estrutura os seguintes insumos: dolomita (pó de mármore), sabão base, carbonato de sódio $\left(\mathrm{Na}_{2} \mathrm{CO}_{3}\right)$, óleo de eucalipto, tensoativos aniônicos, alcalinizante, 


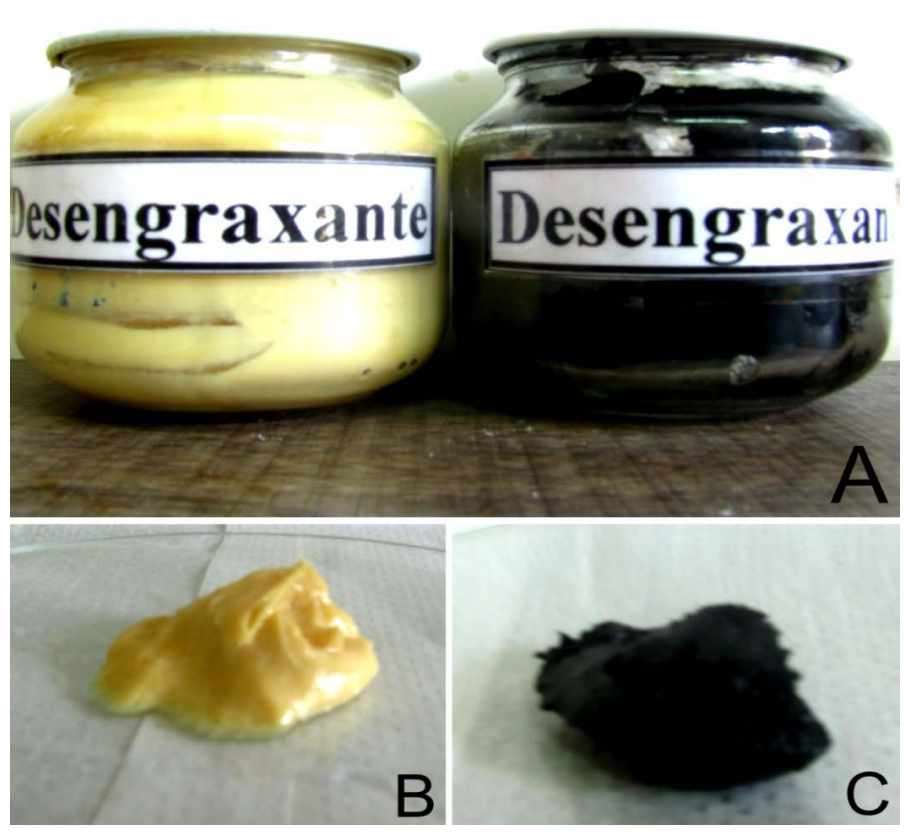

Figura 1a-b. pasta com característica física semi-sólida e arenosa com ação esfoliante. Figura 1a-c. com cor escura e ação abrasiva .

Tabela 1. Custo dos insumos associados a produção do desengraxante, utilizando resíduo de carvão ou mármore.

\begin{tabular}{lcc}
\hline \multicolumn{1}{c}{ Insumos } & Quantidades & $\begin{array}{c}\text { Custo unitário } \\
\text { (R\$) }\end{array}$ \\
\hline & & \\
Massa de sabão sólido & $324 \mathrm{~g}$ & $\mathrm{R} \$ 0,52$ \\
Água & $162 \mathrm{~mL}$ & $\mathrm{R} \$ 0,13$ \\
Carvão vegetal residual (pó) & $10 \mathrm{~g}$ & - \\
Mármore ou granito residual (pó) & $10 \mathrm{~g}$ & - \\
& & $\mathbf{R} \mathbf{0 0 , 6 5}$ \\
\hline
\end{tabular}

anticorrosivo, agente antiredepositante, solvente, conservante, corante, veículo, carga e água. $\mathrm{O}$ produto é comumente encontrado em potes de $500 \mathrm{~g}$ de massa. O preço médio de venda ao consumidor é de 8,00. A metodologia apresentada neste estudo propõe a obtenção de um desengraxante com sabão base produzido a partir do óleo vegetal residual e resíduo de carvão vegetal, e/ou mármore, granito. $\mathrm{O}$ custo para produção desta massa de $500 \mathrm{~g}$ é de aproximadamente $\mathrm{R} \$ 0,65$. O desengraxante obtido pode ser acondicionado em potes de vidro de $115 \mathrm{~g}$, reutilizando um material reciclável e inerte, conforme Figura 1a.

Não foram feitos testes de toxicidade do desengraxante, no entanto, de acordo com o trabalho de Thode-Filho et al. (2014), o sabão produzido com óleo vegetal residual, pode ser uma medida mitigadora para redução do impacto ambiental pro- vocado pelo descarte inadequado do óleo residual. A diferença encontrada entre sabão produzido com óleo vegetal residual e o sabão pastoso vendido comercialmente no varejo é de respectivamente $0,005 \mathrm{~g} / 1000 \mathrm{~mL}(0,005 \mathrm{ppm})$. Verifica-se que para um sabão produzido artesanalmente essa diferença torna-se aceitável, em relação a um sabão industrializado, produzido em larga escala, que utiliza o óleo residual como insumo principal, porém outros insumos virgens para estabilidade da sua composição. Neste sentido, verifica-se que aproximadamente $60 \%$ do desengraxante é composto pelo sabão sólido produzido com óleo vegetal residual. O restante da composição contempla outros dois insumos: água e o resíduo de rochas, conforme descrito na metodologia.

$\mathrm{O}$ crescimento acelerado do consumo populacional tem contribuído para o aumento 
da geração de resíduos nos grandes centros urbanos, no qual requer uma atenção especial quanto à necessidade de saber como descartá-lo. Em tempos modernos, existem diversos procedimentos e técnicas de como gerenciar esses resíduos, portanto muitas pessoas ainda não contribuem com o meio ambiente e acabam descartando de maneira inadequada este resíduo (ENVOLVERDE, 2011). Portanto, neste trabalho são sugeridas novas metodologias na tentativa de reduzir-se o descarte inadequado destes resíduos.

Em cidades onde não há rede de esgoto, os resíduos oleosos provenientes de cozinha são descartados em aterros ou terrenos baldios, provocando graves prejuízos ambientais, visto que são de difícil decomposição. Quando descartados dessas duas formas podem impermeabilizar o solo, dificultando a penetração da água, gerando enchentes e afetando a renovação dos lençóis freáticos e mananciais. Também por se tratar de um material orgânico sua decomposição gera metano, um dos grandes geradores do efeito estufa. Já em cidades onde existe rede de esgoto, quando este mesmo óleo é descartado nas pias causa entupimento da rede coletora e, posteriormente, o mau funcionamento da estação de tratamento, e mesmo após a água ter sido tratada a sua qualidade fica comprometida. Outro problema desse descarte inadequado na pia da cozinha é que nem sempre a companhia de esgoto da cidade recolhe todos os resíduos, sendo parte despejada em mananciais, lagos, rios, represas, etc. Neste caso, como o óleo é menos denso que a água ele formará uma película delgada sobre a superfície dos corpos de água, impossibilitando a troca gasosa com a atmosfera. Isso leva a um acúmulo de grande quantidade de dióxido de carbono dissolvido na água, comprometendo a vida no ecossistema local (MARTINEZ, 2006; AZEVEDO et al., 2009; ALAMINI \& BARBADO 2008).

Para dar conta de tais problemas, é necessário buscar alternativas tecnológicas e gerenciais de controle e prevenção da poluição como, por exemplo, o reuso do óleo vegetal residual de fritura no processo de saponificação. O sabão é um produto obtido a partir de uma hidrólise alcalina de uma gordura de origem vegetal ou animal. Além dos saponáceos, como sabão em barra, detergente líquido e sabão pastoso, o óleo vegetal residual pode ser matéria prima para outros produtos, tais como: biodiesel, óleo para engrenagens, glicerina automotiva, tintas, entre outros (NOGUEIRA \& BEBER, 2009; WILDNER \& HILLIG, 2012). Adicionalmente, no processo de saponificação descrito neste trabalho, além da reciclagem do óleo, ocorre também a reutilização de outros materiais residuais potencialmente poluidores.

\section{CONCLUSÃO}

Este trabalho apresentou a possibilidade de obtenção de dois bioprodutos como alternativas de mitigação do impacto ambiental, provocado pelo descarte inadequado do óleo vegetal residual. Os processos simplificados, as matérias-primas não dispendiosas e os equipamentos rotineiros estimulam positivamente a sua produção. Outro aspecto importante é a utilização de materiais residuais na sua composição o que permite um ciclo de vida estendido a estes materiais que outrora seriam descartados inadequadamente ou potenciais poluidores do ambiente e do meio urbano. Os desengraxantes obtidos podem ser acondicionados em embalagens de vidro ou outros materiais que também podem ter seu ciclo de vida estendido, antes de uma disposição final incorreta, segundo propõe este estudo.

Sugere-se, a partir dos resultados deste estudo, a possibilidade de avaliar as potencialidades de implantação de uma cadeia produtiva de óleo vegetal residual, como forma de minimizar o impacto de seu descarte inadequado e possibilitar a geração de trabalho em renda, através de cooperativas organizadas de catadores.

\section{REFERÊNCIAS}

ALAMINI, B.; BARBADO, N. (2008) Destinação correta para o óleo de Fritura. In: Semana Ambiental: Encontro Técnico-Científico, 5, Foz do Iguaçu, 2008. Resumos, Foz do Iguaçu: União Dinâmica de Faculdades Cataratas, p.31.

AZEVEDO, O. A.; RABBI, M. A.; COELHO NETO, D. M; HARTUIQ, M.H. Fabricação de sabão a partir do óleo comestível residual: Conscientização e Educação Cinetífica. XVIII Simpósio Nacional de Ensino de Física - SINEF 2009 - Vitória ES. Disponível em <http://www.sbfl.sbfisica.org.br/eventos/ snef/xviii/sys/resumos/ T0805-1.pdf> Acesso em 12 Abr. 2011.

ENVOLVERDE. (2011) O Ciclo do Óleo de Cozinha. Disponível em: http://envolverde.com.br/rse/ oleo-de-cozinha. Acesso em: 16 fev 2014. 
FOLHA DO CENTRO. (2009) Esgoto não é lugar de óleo de cozinha. Disponível em: <http://www. jornalfolhadocentro.com.br>. Acesso em: 20 jul. 2012.

MARTINEZ, E. Óleo Vegetal Usado. Instituto de Tecnologia do Pará - TECPAR. 2006. Disponível em <http://sbrt.ibict.br/acessoRT/6344> Acesso em 12 Abr. 2011.

NOGUEIRA, G. R.; BEBER, J. Proposta de metodologia para o gerenciamento de óleo vegetal residual oriundo de frituras. Tese de Mestrado em Bioenergia. Universidade Estadual do Centro-Oeste do Paraná, Irati. 2009. Disponível em: < http://www. unicentro.br>. Acesso em: 14 abr. 2012.

PROVE (2007) Estruturação e Modelagem Funcional. Programa de Reaproveitamento de Óleos Vegetais do Estado do Rio de Janeiro, RJ, Brasil.

RABELO, R. A.; FERREIRA, O. M. Coleta seletiva de óleo residual de fritura para aproveitamento industrial, 2008. Disponível em: <http://www.ucg. br>. Acesso em 14 abr. 2012.

SABESP. Reciclagem de óleo de cozinha, 2011. Disponível em: <http://site.sabesp.com.br>. Acesso em: 14 abr. 2012.

THODE-FILHO, Sergio; SENA, Marcelo Fonseca Monteiro de; SILVA, Elmo Rodrigues; CABRAL, Gabrielle Borges; MARANHÃO, Fabíola da Silveira. (2013) Sistema de análise estequiométrica para produção de sabão a partir do óleo vegetal residual: uma estratégia para redução do impacto ambiental. Revista Eletrônica em Gestão, Educação e Tecnologia Ambiental, (15) 15, 3019-3025.

THODE-FILHO, Sergio; SENA, Marcelo Fonseca Monteiro de; ALMEIDA, Thuanny Moraes de; SILVA, Vinícius da Costa; SILVA, Elmo Rodrigues. (2014) Estudo comparativo da toxicidade do sabão produzido com óleo vegetal residual. Revista Eletrônica em Gestão, Educação e Tecnologia Ambiental,. [no prelo]

WILDNER, L. B. A.: HILLIG, C. (2012) Reciclagem de óleo comestível e fabricação de sabão como instrumentos de educação ambiental. Revista Eletrônica em Gestão, Educação e Tecnologia Ambiental (1), 813-824. 